\title{
Dispersion stability and anti-oxidation of an aqueous Zirconium Diboride slurry with a high solid loading
}

\author{
Joo-Hee SON, Se-Hyuk JUNG and Sung-Churl CHOI ${ }^{\dagger}$ \\ Division of Materials Science Engineering, Hanyang University, Seoul 133-791, Republic of Korea
}

\begin{abstract}
In this paper, the dispersion stability of zirconium diboride $\left(\mathrm{ZrB}_{2}\right)$ slurries and their anti-oxidation behavior to prevent re-oxidation in the $\mathrm{ZrB}_{2}$ slurries were studied.

SPEX-milled $\mathrm{ZrB}_{2}$ powder was used to improve the dispersion stability, and the viscosity and zeta potential as a function of $\mathrm{pH}$ were measured in order to confirm the dispersion behavior in aqueous $\mathrm{ZrB}_{2}$ slurries using various additives [polyethylenimine (PEI), polyacrylicacid (PAA), polyvinyl pyrrolidone (PVP), and polyvinyl alcohol (PVA)]. In addition, the oxygen contents were measured before and after processing to evaluate the oxidation behavior in the $\mathrm{ZrB}_{2}$ slurries.

By using $2 \mathrm{wt} \% \mathrm{PEI}$, the isoelectric point (IEP) of the $\mathrm{ZrB}_{2}$ slurry increased from a pH of 5.8 to above a pH of 12. Also, the viscosity was below $6.27 \mathrm{mPa} \cdot \mathrm{s}$ in the $20 \mathrm{vol} \% \mathrm{ZrB}_{2}$ slurry at $\mathrm{pH}$ values of 2-12. The oxygen content of the $\mathrm{ZrB}_{2}$ powders increased from 2.42 to 3.79 wt \% after preparing an aqueous slurry, but by using 2 wt \% PVP and 2 wt \% PEI, the oxygen contents of the 20 vol \% $\mathrm{ZrB}_{2}$ slurry could be reduced from 3.79 to 2.6 and $2.8 \mathrm{wt} \%$, respectively. Consequently, a 50 vol \% $\mathrm{ZrB}_{2}$ slurry with an oxygen content was $2.92 \mathrm{wt} \%$ could be prepared in the pH range of 6-9 using $2 \mathrm{wt} \%$ PEI.
\end{abstract}

(-2013 The Ceramic Society of Japan. All rights reserved.

Key-words : Dispersion stability, Anti-oxidation, Zirconium Diboride $\left(\mathrm{ZrB}_{2}\right)$, High solid loading, Additives

[Received October 5, 2012; Accepted October 22, 2012]

\section{Introduction}

Ultra High Temperature Ceramics (UHTCs) have been a main subject of recent research in the field of structural ceramics. Among the UHTCs, $\mathrm{ZrB}_{2}$ has a high melting point above $3,200^{\circ} \mathrm{C}$, a Young's modulus of about $500 \mathrm{GPa}$, a hardness of $23 \mathrm{GPa}$, a chemically stable crystal structure, high electrical and thermal conductivities, and good resistance for corrosion. Because of these properties, $\mathrm{ZrB}_{2}$ has been used for refractory and structural materials such as refractory linings, electrodes, micro-electronic technology applications, and cutting tools. $\mathrm{ZrB}_{2}$ has also been considered as a promising candidate for aerospace materials such as hypersonic aircraft, atmosphere re-entry spacecraft, and rocket propellants. ${ }^{1), 2)}$

However, in order to apply this material in usable components, the fabrication of $\mathrm{ZrB}_{2}$ structures with complex geometries is required. A pressureless sintering process including a colloidal process is suitable for manufacturing $\mathrm{ZrB}_{2}$ structures with complex geometries. In addition, complex geometries could be manufactured by using colloidal processing such as slip casting, tape casting, and injection molding. Dispersion stability and a high solid loading in slurries are essential during the colloidal process. Therefore, additives have been used to increase the dispersion stability and mechanical treatment has been applied to decrease the particle size. ${ }^{3)}$

Many researchers have been investigated the dispersion stability of $\mathrm{ZrB}_{2}$ slurries using various additives. ${ }^{3)-8)}$ Generally, the mechanism for enhancing the dispersion stability by using additives can be divided into four categories. First, in electrostatic stabilization, the dispersion effect is improved due to repulsive forces between like charges. There is an energy barrier large

\footnotetext{
Corresponding author: S.-C. Choi; E-mail: choi0505@hanyang. ac.kr
}

enough to overcome the attractive van der waals forces between the particles. Second, steric stabilization may be present such that particles cannot approach each other due to the adsorption of organic polymer on the surfaces of particles. Third, electrosteric stabilization is a combination of electrostatic stabilization and steric stabilization. Finally, controlling the dispersion and agglomeration by macromolecules between the particles and not absorbed on the surfaces of particles is referred to as depletion stabilization. ${ }^{9)}$ In this study, four different additives were used and their properties are summarized in Table 1.

$\mathrm{ZrB}_{2}$ has a low intrinsic sinterability due to its strong covalent bonding, low self-diffusion coefficient, and surface oxide impurities. In particular, oxide impurities on the surface of $\mathrm{ZrB}_{2}$ powder such as $\mathrm{ZrO}_{2}$ or $\mathrm{B}_{2} \mathrm{O}_{3}$ interrupt densification. The oxide impurities lead to low bulk and grain boundary diffusion rates. In addition, the oxide impurities supply a rapid diffusion passage to accelerate coarsening. During the grain coarsening, the surface area of the particles decreases reducing the driving force for densification. ${ }^{10)-12)}$ Oxide impurities are formed by oxidation reactions with $\mathrm{H}_{2} \mathrm{O}$ or alcohol in the solvent. ${ }^{13), 14)}$ It is considered that the oxidation reactions can be prevented by coating a polymer layer on the surface of the powder using additives.

In this study, we investigated the dispersion stability and antioxidation behavior in aqueous $\mathrm{ZrB}_{2}$ slurries using various additives (PEI, PAA, PVP, and PVA) and discuss their mechanisms.

\section{Experimental procedure}

$\mathrm{ZrB}_{2}$ (Grade: $\mathrm{ZrB}_{2}-\mathrm{F}$, Japan New Metals Co., Osaka, Japan) powder with an average particle size of $2.42 \mu \mathrm{m}$ and an oxygen content of $1.23 \mathrm{wt} \%$ was used as the starting material. PEI (Sigma Aldrich Corp., St. Louis, MO, USA; molecular weight (MW): 10,000), PAA (Sigma Aldrich Corp., St. Louis, MO, USA; molecular weight (MW): 1,800), PVP (Sigma Aldrich Corp., St. Louis, MO, USA; molecular weight (MW): 40,000), 
Table 1. Characteristics of the various additives

\begin{tabular}{cccc}
\hline & PEI & good & good \\
\hline Structural formula & soluble in hot water & electrostatic \\
stabilization & stabilization & good \\
\hline $\begin{array}{c}\text { She type of dispersion } \\
\text { stabilization }\end{array}$ & stabilization & & stabilization \\
\hline
\end{tabular}

Table 2. $\mathrm{ZrB}_{2}$ slurries produced under various conditions

\begin{tabular}{ccc}
\hline Solid loading (vol \%) & Type of additives & Amount of additive (wt \%) \\
\hline \multirow{2}{*}{20} & PEI & \\
& PVA & 2 \\
& PVP & \\
\hline & PAA & 0.5 \\
& & 1 \\
20 & & 2 \\
& PEI & 3 \\
& & 4 \\
& & 5 \\
\hline 30 & & \\
40 & & \\
50 & PEI & \\
\hline
\end{tabular}

and PVA (Sigma Aldrich Corp., St. Louis, MO, USA; molecular weight (MW): 89,000-98,000) were used as additives. $\mathrm{ZrB}_{2}$ powders were pulverized by a SPEX mill (model $8000 \mathrm{D}$, SpexCertiprepInc., Metucher, NJ, USA) for $6 \mathrm{~h}$ using a WC jar and media. The particle size of the $\mathrm{ZrB}_{2}$ powder was measured by a particle size analyzer (LA-950V2, HORIBA Ltd., Kyoto, Japan) before and after milling.

The batch conditions including the additives, compositions, and the solid loading amounts are shown in Table 2. The $\mathrm{ZrB}_{2}$ powder and additives were mixed in DI water and stirred for $24 \mathrm{~h}$. The viscosity and zeta potential as a function of $\mathrm{pH}$ of the stirred slurries were measured by a rheometer (Thermo SCIENTIFIC HAAKE MARSIII, MCIK, Seoul, Korea) and a zeta potential analyzer (ELSZ, OtsukaElectronics Co., LTD, Japan), respectively, where diluted $\mathrm{HCl}$ and $\mathrm{NaOH}$ solutions were used for the titration. Before and after colloidal processing, the oxygen contents of the $\mathrm{ZrB}_{2}$ powders were measured by using the combustion gas hot extraction method (Model TC-600, LECO Co., St. Joseph, MI, USA) in order to confirm the oxidation behavior of the $\mathrm{ZrB}_{2}$ slurries.

\section{Results and discussion}

The particle size distributions of the as-received and SPEXmilled $\mathrm{ZrB}_{2}$ powders are shown in Fig. 1. In Fig. 1, both the as-received and milled $\mathrm{ZrB}_{2}$ powders have mono particle size distributions where the milled powder is more pronounced in the fine area than the as-received powder. The average particle sizes of the as-received and milled powders were 2.42 and 0.51 $\mu \mathrm{m}$, respectively, demonstrating that the particle size decreased significantly after milling.

The oxygen contents of the as-received $\mathrm{ZrB}_{2}$ powder increased from 1.23 to $2.41 \mathrm{wt} \%$ after milling. It is considered that the acceleration of the oxidation reaction resulted from heat gen-

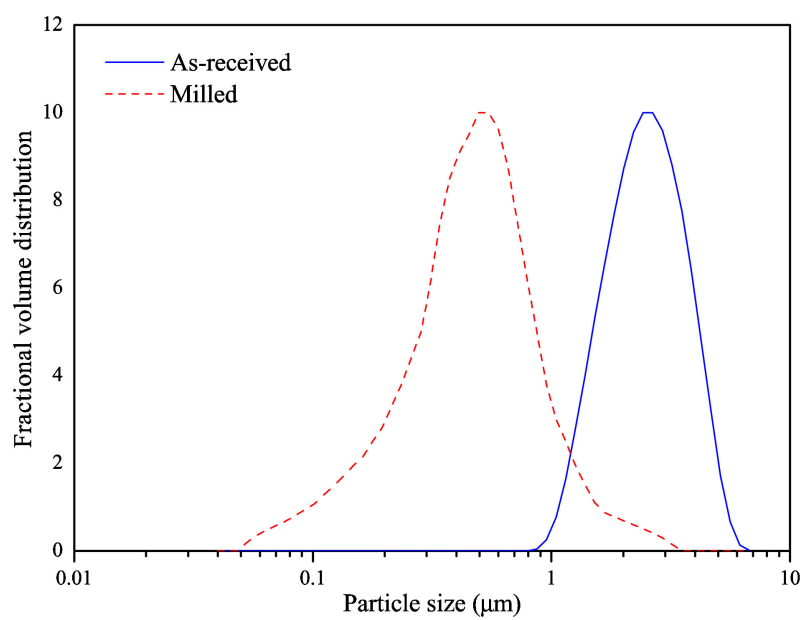

Fig. 1. (Color online) Particle size distributions of as-received and SPEX-milled $\mathrm{ZrB}_{2}$ powders.

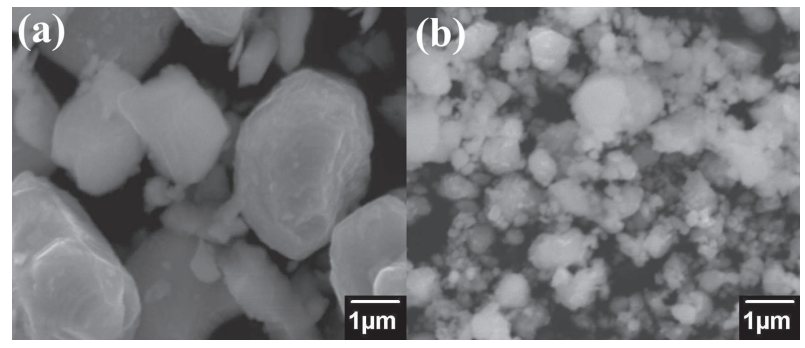

Fig. 2. Scanning electron microscope images of the (a) as-received and (b) SPEX-milled powders.

erated by collisions between the WC jar and media and increased surface area resulting from the decreased particle size after SPEX milling.

Figure 2 shows the powder morphologies of the as-received and SPEX-milled $\mathrm{ZrB}_{2}$ powders. Most of the particles have a spherical shape and the particle size decreased significantly after milling. It is considered that the decreased particle size due to the milling process is effective to increase the dispersion stability by decreasing gravity effects. The behavior can be confirmed by Eq. (1).

$$
\mathrm{V}_{\mathrm{s}}=\mathrm{g}\left(\rho_{\mathrm{s}}-\rho_{1}\right) \mathrm{d}^{2} / 18 \eta
$$

Here, $V_{s}$ is the Stokes velocity, $g$ is the acceleration of gravity, $\rho_{\mathrm{s}}$ is the density of the solid particles, $\rho_{1}$ is the liquid density, $\mathrm{d}$ is the size of a single particle, and $\eta$ is the fluid viscosity. ${ }^{15}$ )

Figure 3 shows the viscosity as a function of the $\mathrm{pH}$ in the $\mathrm{ZrB}_{2}$ slurry with the various additives. With PVP and PVA, the viscosity changed significantly as a function of $\mathrm{pH}$ and it was relatively higher than the viscosities with the other additives. On 


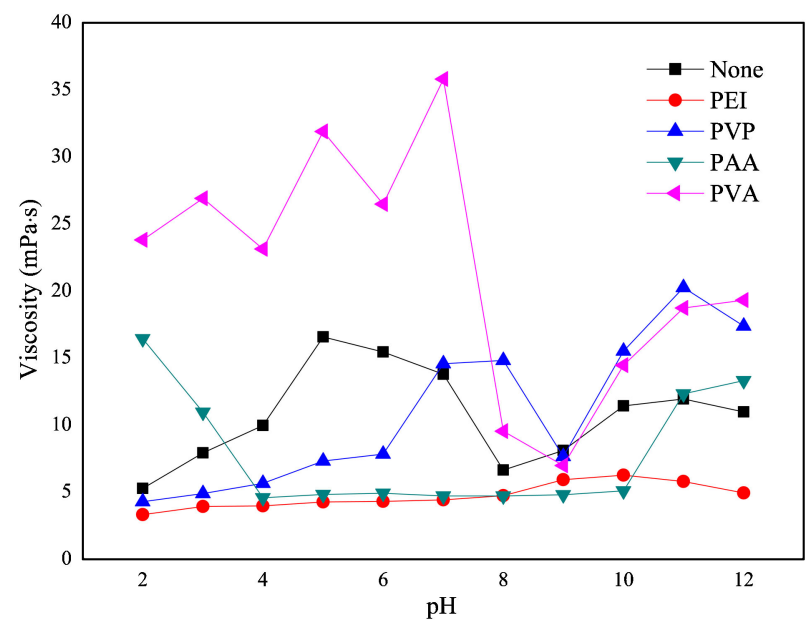

Fig. 3. (Color online) Viscosity of the $20 \mathrm{vol} \% \mathrm{ZrB}_{2}$ slurries containing $2 \mathrm{wt} \%$ of the various additives.

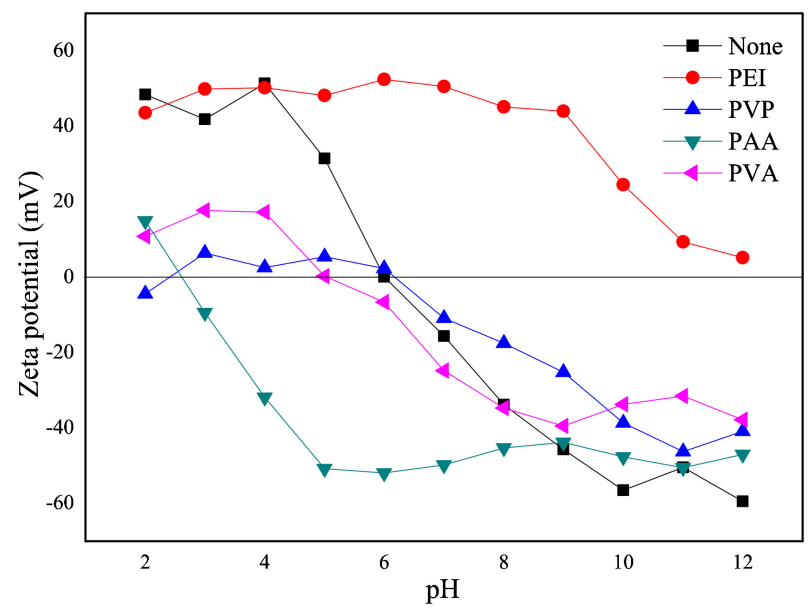

Fig. 4. (Color online) Zeta potential of the $\mathrm{ZrB}_{2}$ slurries containing $2 \mathrm{wt} \%$ of the various additives.

the other hand, the $\mathrm{ZrB}_{2}$ slurry with PEI was the most stable because it had a low viscosity in the overall $\mathrm{pH}$ range. The $\mathrm{ZrB}_{2}$ slurry with PAA is also stable with a low viscosity of less than $6.27 \mathrm{mPa} \cdot \mathrm{s}$ in the $\mathrm{pH}$ range of $4-10$.

Also, the viscosities of the $\mathrm{ZrB}_{2}$ slurry with PEI or PAA were lower than those of the slurry without an additive. Generally, the viscosity decreases along with an improvement of the dispersion stability. ${ }^{3), 16), 17)}$ Therefore, it is considered that the lower viscosity is due to electrostatic stabilization by PEI and PAA. These results demonstrate that PEI and PAA are more effective additives for dispersion in the $\mathrm{ZrB}_{2}$ slurries.

The zeta potentials as a function of $\mathrm{pH}$ with the four additives are shown in Fig. 4. The zeta potential represents the amount of charge on the surface of the particles in the slurry. A high absolute value of the zeta potential indicates effective dispersion due to strong repulsion between particles.

In Fig. 4, PEI and PAA are the most effective additives for dispersion. By using PAA and PEI, the isoelectric point (IEP) of the $\mathrm{ZrB}_{2}$ slurry shifted from a $\mathrm{pH}$ of 5.8 to a $\mathrm{pH}$ of 2.75 and a $\mathrm{pH}$ above 12. The absolute values of the zeta potential in the $\mathrm{ZrB}_{2}$ slurries with PEI and PAA are the highest above a $\mathrm{pH}$ of 5 and below a $\mathrm{pH}$ of 9 , respectively. These highest absolute values of the zeta potential may be effective for dispersion due to the strong repulsion between particles.

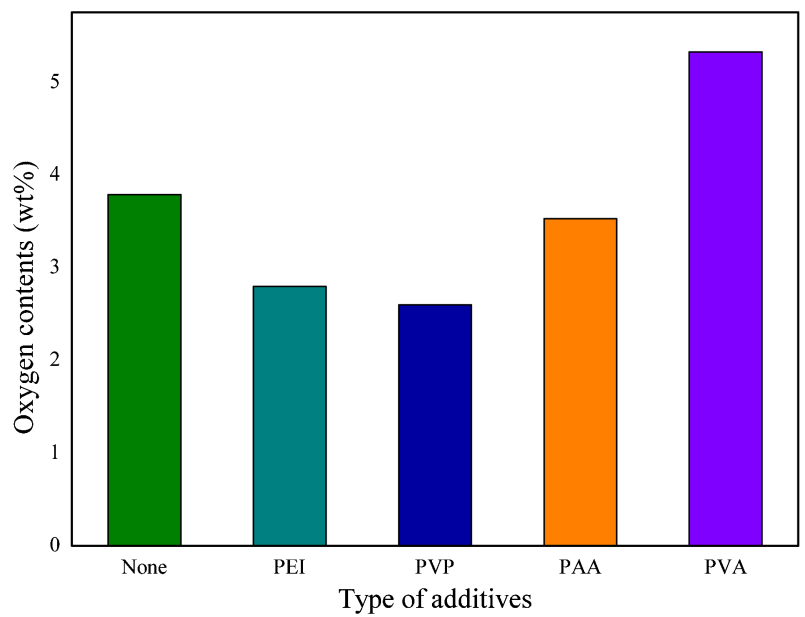

Fig. 5. (Color online) Oxygen contents of the $\mathrm{ZrB}_{2}$ in $20 \mathrm{vol} \% \mathrm{ZrB}_{2}$ slurries containing $2 \mathrm{wt} \%$ of the various additives.

Table 3. Effects of the additives on the dispersion stability, viscosity, and anti-oxidation behavior of the slurries

\begin{tabular}{ccccc}
\hline & PEI & PAA & PVP & PVA \\
\hline Dispersion stability & $\bigcirc$ & $\bigcirc$ & $\triangle$ & $\times$ \\
\hline Viscosity & low & low & middle & high \\
\hline Anti-oxidation & $\bigcirc$ & $\triangle$ & $\bigcirc$ & $\times$ \\
\hline
\end{tabular}

○: Good, $\triangle$ : Normal, $\times$ : Bad.

On the other hand, the absolute values of the zeta potential in the $\mathrm{ZrB}_{2}$ slurry with PVP and PVA are lower than those in the slurry without an additive. These results showed the same trend of the above mentioned viscosity data shown in Fig. 3.

In this study, the dispersion stability in the $\mathrm{ZrB}_{2}$ slurry and the anti-oxidation behavior of the $\mathrm{ZrB}_{2}$ powder in the slurry were studied. Tieshu Huang et al. reported that the $\mathrm{pH}$ does not have a significant effect on the oxidation rate in $\mathrm{ZrB}_{2}$ slurries. ${ }^{3)}$ Therefore, the experiments were carried out at a fixed $\mathrm{pH}$ of 7 . The oxygen contents of the $\mathrm{ZrB}_{2}$ powders in the slurries with the four additives are shown in Fig. 5. The oxygen content of the milled $\mathrm{ZrB}_{2}$ powders increased from 2.41 to $3.79 \mathrm{wt} \%$ during the colloidal process. It is considered that the oxygen contents increased by the oxidation reaction with the water used as the solvent.

Also, the oxygen contents of the $\mathrm{ZrB}_{2}$ powders in the slurries with the different additives except for PVA were lower than that of the powder in the slurry without an additive. It is considered that the oxidation reaction was prevented by a polymer coating layer on the surface of the $\mathrm{ZrB}_{2}$ particles. On the other hand, the oxygen content in the slurry with PVA was higher than that without an additive. In addition, it is considered that the oxidation reaction occurred due to the $\mathrm{OH}$ functional groups of PVA. Among the three effective additives for anti-oxidation, the oxygen content of the $\mathrm{ZrB}_{2}$ powder in the slurry with PVP was the lowest at $2.60 \mathrm{wt} \%$, but the dispersion stability was not good, as shown in Figs. 3 and 4. The $\mathrm{ZrB}_{2}$ slurries with PAA or PEI have good dispersion stabilities but the oxygen contents are 3.53 and $2.80 \mathrm{wt} \%$, respectively. As a result, PEI is a more effective additive for anti-oxidation. From these results, PEI is the most effective additive which simultaneously improves the dispersion stability and anti-oxidation properties, as summarized in Table 3. 


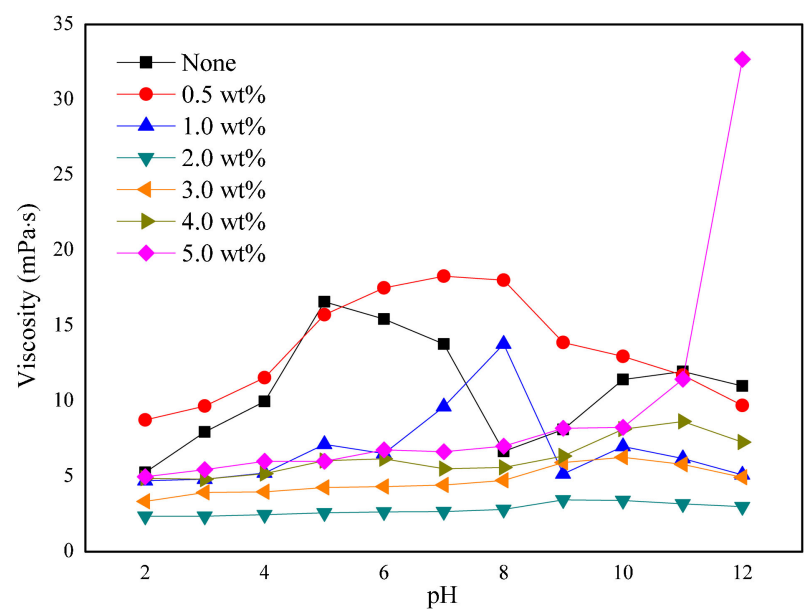

Fig. 6. (Color online) Viscosity of the $20 \mathrm{vol} \% \quad \mathrm{ZrB}_{2}$ slurry as a function of the PEI content.

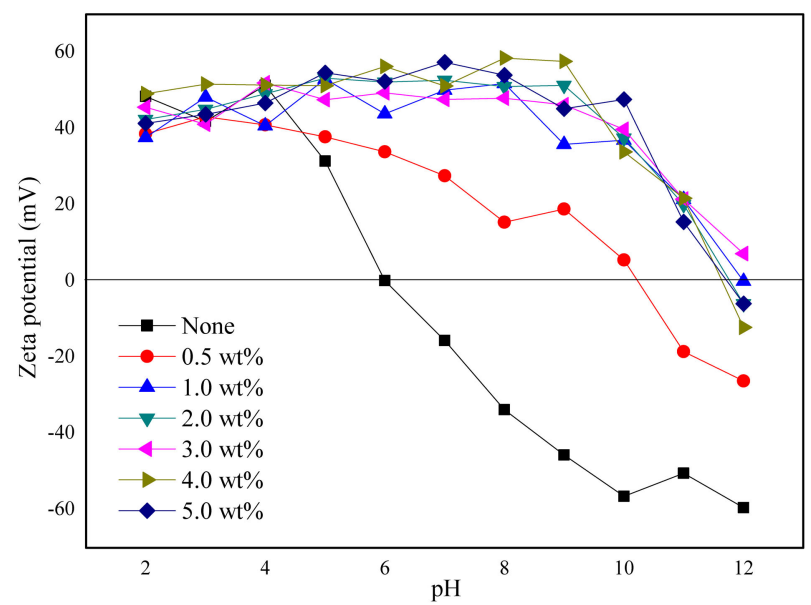

Fig. 7. (Color online) Zeta potential of the $\mathrm{ZrB}_{2}$ slurry as a function of the PEI content.

The viscosity as a function of the amount of PEI in the $\mathrm{ZrB}_{2}$ slurry is shown in Fig. 6. The viscosity decreased with increasing PEI content up to $2 \mathrm{wt} \%$ but then increased above $3 \mathrm{wt} \%$. When two surfaces covered by a macromolecule approach each other, steric repulsion is activated due to the polymer coating. However, it is also possible that the same polymer molecule may absorb to more than one particle at the same time, thereby forming a link between particles. This phenomenon is called bridging flocculation and produces an unstable slurry. ${ }^{18)}$ It is considered that the viscosity of the $\mathrm{ZrB}_{2}$ slurries with more than $3 \mathrm{wt} \%$ PEI increased by this bridging flocculation. Therefore, the slurry with $2 \mathrm{wt} \%$ PEI, which had the lowest viscosity, is the optimum condition for dispersion.

Figure 7 shows the zeta potential of $\mathrm{ZrB}_{2}$ as a function of the PEI content. The zeta potential increased with the addition of PEI and the zeta potential of the slurry with over $1 \mathrm{wt} \%$ PEI maintained a high value in the $\mathrm{pH}$ range of 2-9. It can be found that $\mathrm{ZrB}_{2}$ particles in the slurry were stably charged on the surface in the $\mathrm{pH}$ range of 2-9.

In Figs. 6 and 7, the absolute values of the zeta potentials of the slurries with over $1 \mathrm{wt} \%$ PEI were very similar, but the viscosity was the lowest in the slurry with $2 \mathrm{wt} \%$ PEI. Therefore, it is considered that the addition of $2 \mathrm{wt} \%$ PEI is optimal for dispersion stability.

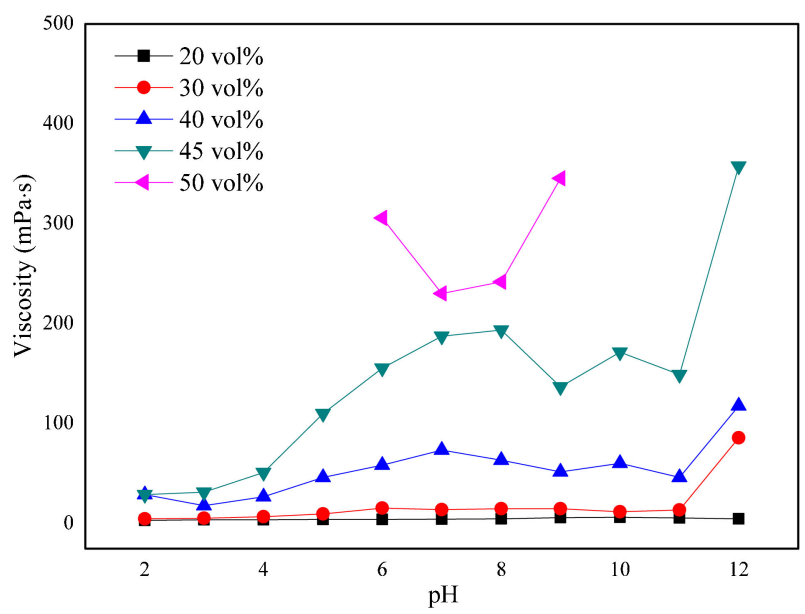

Fig. 8. (Color online) Viscosity of the $\mathrm{ZrB}_{2}$ slurry as a function of the solid loading contents with 2 wt $\%$ PEI.

The viscosities of the slurries with $2 \mathrm{wt} \% \mathrm{PEI}$ as a function of the solid loading are shown in Fig. 8. The viscosity increased with increasing solid loading amount from 20 to $50 \mathrm{vol} \%$. We were able to fabricate $\mathrm{ZrB}_{2}$ slurries with a high solid loading of up to $50 \mathrm{vol} \%$ in the $\mathrm{pH}$ range of 6-9 with an oxygen content of $2.92 \mathrm{wt} \%$. The viscosity of the slurries with solid loadings over 50 vol\% could not be measured and the dispersion could not be maintained because of sedimentation. Also, the viscosities in the slurries with solid loadings of 20 and 30 vol $\%$ maintained similar low values. The viscosity of the slurry with solid loadings over $40 \mathrm{vol} \%$ significantly increased with increasing solid loading.

Therefore, it is considered that the addition of $2 \mathrm{wt} \% \mathrm{PEI}$ is the most effective for dispersion stability and anti-oxidation in the $\mathrm{ZrB}_{2}$ slurry.

\section{Conclusions}

In this study, the dispersion stability of $\mathrm{ZrB}_{2}$ slurries and anti-oxidation behavior for preventing re-oxidation in the $\mathrm{ZrB}_{2}$ slurries using additives (PEI, PAA, PVP, and PVA) were studied. The viscosity and zeta potential were measured to determine the most effective additive for dispersion stability. The viscosities in the slurries with PEI and PAA were lower than with the other additives because of the stability resulting from electrostatic stabilization. The zeta potential values also showed the same tendency.

The oxygen contents of the $\mathrm{ZrB}_{2}$ powders were measured to determine the most effective additive for anti-oxidation. By using $2 \mathrm{wt} \%$ PEI and $2 \mathrm{wt} \%$ PVP, the oxygen contents of the milled $\mathrm{ZrB}_{2}$ powders decreased from 3.79 to 2.80 and $2.60 \mathrm{wt} \%$, respectively. It is considered that the oxidation reaction was prevented by a polymer coating layer on the surface of the $\mathrm{ZrB}_{2}$ particles. From these results, PEI is the most effective additive which simultaneously provides dispersion stability and antioxidation characteristics.

For the PEI additive, the viscosity and zeta potential were measured to understand the dispersion stability as a function of the amount of PEI. As a result, 2 wt \% PEI was the optimal condition for dispersion stability.

As a result, by using $2 \mathrm{wt} \%$ PEI, the 50 vol $\%$ solid loading $\mathrm{ZrB}_{2}$ slurry could be prepared in the $\mathrm{pH}$ range of 6-9 and its oxygen content was $2.92 \mathrm{wt} \%$. 
Acknowledgement This research was supported by NSL (National Space Lab) program through the National Research Foundation of Korea funded by the Ministry of Education, Science and Technology (2009-0091916)

\section{References}

1) R. Telle, L. S. Sigl and K. Takagi, "Boride-Based Hard Materials", Ed. by R. Riedel, Handbook of Ceramic Hard Materials, Wiley-VCH, Weinheim (2000) pp. 802-945.

2) W. G. Fahrenholtz, G. E. Hilmas, I. G. Talmy and J. A. Zaykoski, J. Am. Ceram. Soc., 90, 1347-1364 (2007).

3) T. Huang, G. E. Hilmas and W. G. Fahrenholtz, Int. J. Appl. Ceram. Technol., 4, 470-479 (2007).

4) S. H. Lee, Y. Sakka and Y. Kagawa, J. Am. Ceram. Soc., 90, 3455-3459 (2007).

5) J. Sun and L. Gao, J. Eur. Ceram. Soc., 21, 2447-2451 (2001).

6) S. Wildhack, G. Rixecker and F. Aldinger, J. Am. Ceram. Soc., 88, 2391-2395 (2005).

7) A. B. Bourlinos, V. Georgakilas, R. Zboril, T. A. Steriotis, A. K. Stubos and C. Trapalis, Solid State Commun., 149,
2172-2176 (2009).

8) A. W. M. de Laat and W. P. T. Derks, Colloids Surf. A, 71, 147-153 (1993).

9) J. A. Lewis, J. Am. Ceram. Soc., 83, 2341-2359 (2000).

10) S. Zhu, W. G. Fahrenholtz, G. E. Hilmas and S. C. Zhang, Mater. Sci. Eng., A, 459, 167-171 (2007).

11) M. Thompson, W. G. Fahrenholtz and G. E. Hilmas, J. Am. Ceram. Soc., 94, 429-435 (2011).

12) J. Zou, G. J. Zhang, S. K. Sun, H. T. Liu, Y. M. Kan, J. X. Liu and C. M. Xu, J. Eur. Ceram. Soc., 31, 421-427 (2011).

13) S. H. Lee, Y. Sakka and Y. Kagawa, J. Am. Ceram. Soc., 91, 1715-1717 (2008).

14) S. Wildhack, G. Rixecker and F. Aldinger, J. Am. Ceram. Soc., 88, 2391-2395 (2005).

15) A. S. Rao, Ceram. Int., 14, 49-57 (1988).

16) R. Greenwood and L. Bergström, J. Eur. Ceram. Soc., 17, 537548 (1997).

17) K. Sato, H. Yilmaz, Y. Hotta, A. Ijuin and K. Watari, J. Am. Ceram. Soc., 92, 256-259 (2009).

18) K. Sato, H. Yilmaz, Y. Hotta, A. Ijuin and K. Watari, J. Am. Ceram. Soc., 92, 256-259 (2009). 